\title{
Nitrous Oxide Induced Subacute Combined Degeneration
}

\author{
Huimin Zhao, Zhongmin We, Yingying Xu \\ Department of Neurology, The Second Affiliate Hospital of Soochow University, Suzhou, China.
}

\section{Corresponding Author: \\ Dr. Yingying Xu \\ Email: xyy3564@163.com}

This is an Open Access article distributed under the terms of the Creative Commons Attribution License (creativecommons.org/ licenses/by/3.0).

Received Accepted

Published

February 11, 2019

August 21, 2019

September 30, 2019

\begin{abstract}
Background: Nitrous oxide $\left(\mathrm{N}_{2} \mathrm{O}\right)$, due to its euphoriant properties is often abused for recreational purpose. Case Report: A 38-year-old male who admitted to inhaling recreational nitrous oxide more than five months, presented with a progressive symmetrical tingling sensations and weakness of limbs. Serum vitamin $\mathrm{B}_{12}$ was lower than normal. Magnetic resonance imaging (MRI) of the spine demonstrated hyperintensity of the posterior cord extending from C1-C5. Nerve conduction velocity test showed slowed motor conduction velocities and delayed or absent F-waves consistent with demyelinating neuropathy. The patient was managed with $\mathrm{B}_{12}$ supplement and his nerve function basically returned to normal after three months. Conclusion: This is a rare case of subacute combing degeneration caused by excessive inhalation of nitrous oxide.
\end{abstract}

Keywords: Demyelinating Diseases, Magnetic Resonance Imaging, Neural Conduction, Nitrous Oxide, Vitamin B12.

\section{Introduction}

Nitrous oxide $\left(\mathrm{N}_{2} \mathrm{O}\right)$ is used commonly for surgical procedures and as a propellant in the food industry [1]. However, due to its euphoriant properties, $\mathrm{N}_{2} \mathrm{O}$ now is often abused for recreational purpose. Very few cases of the neurological syndrome caused by excessive inhalation of $\mathrm{N}_{2} \mathrm{O}$ were reported [2-6]. We report the clinical presentation, electrophysiological examination results and radiological manifestations of $\mathrm{N}_{2} \mathrm{O}$ induced subacute combined degeneration.

\section{Case Report}

A 28-year-old previously healthy male presented with progressive inability to walk properly and symmetrical numbness and tingling sensations in his distal extremities within nearly six days. He also complained difficulty to perform fine tasks with his hands. He felt cervicodorsal tingling sensations prior to the onset of symptoms. He had no sphincter dysfunction and other autonomic symptoms and any history of trauma or recent illness was denied.
He admitted to inhaling recreational $\mathrm{N}_{2} \mathrm{O}$ in the form of small pressurised canisters for one year. His consumption of $\mathrm{N}_{2} \mathrm{O}$ was greatly increased over the last five months and approximately 800 grams (100 whippits) for once or twice a week. Ten days before the symptoms onset, he used $1200 \mathrm{~g}$ at a time. Except a history of pneumothorax operation, no special past medical history and family history were recorded.

On examination his cognition, cranial nerve function and muscle tone were normal. He had symmetrical distal weakness of the lower and upper limbs along with a glove and sock-like hyperpathia. He walked with a broad-based gait, and Romberg's sign was positive. Deep tendon reflexes were normal. Position and vibration sense were impaired in both upper and lower extremities. The Babinski's sign was positive.

The results of thyroid stimulating hormone, coagulation testing, liver and kidney function, plasma glucose, routine blood test, routine urine 
test, serum folate were normal. Serum vitamin $\mathrm{B}_{12}$ was low at $150.24 \mathrm{pg} / \mathrm{mL}$ (normal range = $180-914 \mathrm{pg} / \mathrm{mL})$. Homocysteine was high at $62.9 \mu \mathrm{mol} / \mathrm{L}$ (normal range $=5-15 \mu \mathrm{mol} / \mathrm{L}$ ). He underwent magnetic resonance imaging (MRI) scan of his spinal cord, which revealed hyperintensity of the posterior cord from $\mathrm{C} 1-\mathrm{C} 5$ [Fig.1-4]. No abnormalities were seen on MRI brain. Nerve conduction studies showed slowed motor conduction velocities and delayed or absent F-waves, consistent with demyelinating neuropathy. Based on the history, clinical presentation, image findings and laboratory tests, he was diagnosed as subacute combined degeneration (SCD) caused by $\mathrm{N}_{2} \mathrm{O}$ abuse.

The patient was treated with high-dose intravenous vitamin $\mathrm{B}_{12}$ supplementation $(1500 \mu \mathrm{g}$ per day) for the first two weeks. His balance and gait improved gradually as well as the involuntary movement after treatment. With rehabilitation, he could walk independently slowly. After the discharge, the patient has continued to be treated with oral vitamin $B_{12}$ supplement (500 $\mu \mathrm{g}$ three times a day). After three months, the patient's symptoms basically returned to normal by telephone follow-up.

\section{Discussion}

For more than 150 years, $\mathrm{N}_{2} \mathrm{O}$ has been widely applied in dentistry and surgery for its analgesic and anesthetic properties. It has lately gained popularity as a recreational drug, and its use is widespread. Acute poisoning of $\mathrm{N}_{2} \mathrm{O}$ can cause low blood pressure, lung injury due to hypoxia, and even asphyxia. Chronic poisoning mainly presents as anemia and neurological damage. At present, most countries have not included $\mathrm{N}_{2} \mathrm{O}$ under the category of drug administration.

Several case studies have reported neurological damage caused by $\mathrm{N}_{2} \mathrm{O}$ abuse, including cognitive impairment, peripheral nerve and spinal damage. In our case, the serum vitamin $\mathrm{B}_{12}$ of patient was lower than normal, while, some
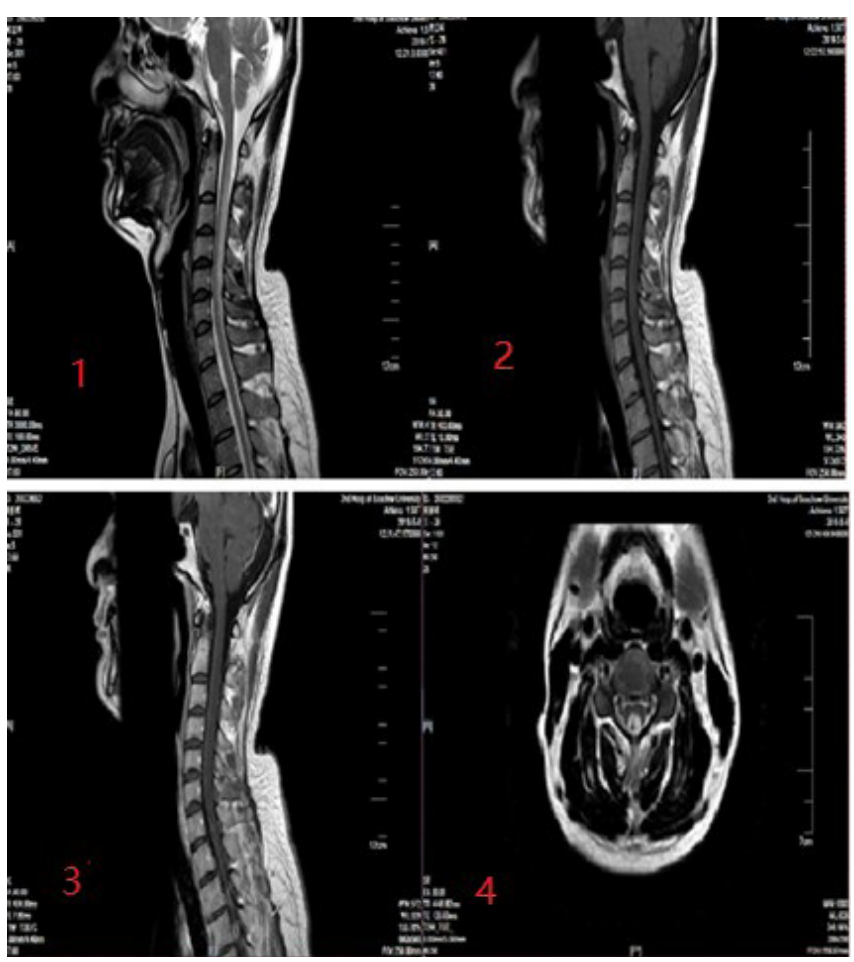

Fig.1-4: Magnetic resonance imaging (MRI) scan of spinal cord, which revealed hyper-intensity of the posterior cord from $\mathrm{Cl}$-C5.

case reports reported normal vitamin $B_{12}$ levels [3]. A normal vitamin $\mathrm{B}_{12}$ level does not rule out the possibility of $\mathrm{N}_{2} \mathrm{O}$-induced subacute degeneration of the spinal cord, given that functional vitamin $\mathrm{B}_{12}$ deficiency can occur in the presence of normal serum vitamin $B_{12}$ levels. Slowed motor conduction velocities and delayed or absent F-waves also contributes to the diagnosis of subacute combined degeneration. In this case, detecting raised homocystine, which rely on normally functioning vitamin $\mathrm{B}_{12}$ for their metabolism, can give crucial clues to the diagnosis [7-8]. To best of our knowledge, 19 cases of SCD caused by $\mathrm{N}_{2} \mathrm{O}$ abuse have been reported till date. To date, evaluated with MRI and electrophysiological examination at same time, this is the first case of $\mathrm{N}_{2} \mathrm{O}$ induced subacute combined degeneration patient reported in the mainland of China.

In European and American countries, the rate of $\mathrm{N}_{2} \mathrm{O}$ abuse is as high as $15.8 \%$ among teenagers [9]. Although there's no exact statistics 
about $\mathrm{N}_{2} \mathrm{O}$ abuse in mainland of China, there's a rising trend of the patients who were diagnosed as $\mathrm{N}_{2} \mathrm{O}$ poisoning in clinical setups. This phenomenon should attract the attention of relevant government departments, and related measures should be taken.

\section{Conclusion}

Although subacute degeneration caused by $\mathrm{N}_{2} \mathrm{O}$ is rare, with the increase of $\mathrm{N}_{2} \mathrm{O}$ abuse population, early identification of $\mathrm{N}_{2} \mathrm{O}$-induced neuropathy is critical for its property of being reversible.

Contributors: HZ: manuscript editing, patient management; ZW: manuscript writing, patient management; YX: critical inputs into the manuscript and patient management. YX will act as a study guarantor. All authors approved the final version of this manuscript.

Funding: None; Competing interests: None stated.

\section{References}

1. Thompson AG, Leite MI, Lunn MP, Bennett DL. Whippits, nitrous oxide and the dangers of legal highs. Pract Neurol. 2015;15:207-209.

2. Wang L, Fan Q, Dong M, Tian Z, Wang R, Gu W, et al. Nervous system disorder caused by nitrous oxide intoxication: one case report. Chin J Contemp Neurol Neurosurg, 2016;16(8):533-536.

3. Yuan JL, Wang SK, Jiang T, Hu WL. Nitrous oxide induced subacute combined degeneration with longitudinally extensive myelopathy with inverted V-sign on spinal MRI: a case report and literature review. BMC Neurology. 2017;17:222-225.

4. Xiaoyan L, Yuanfang L, Jia J, Peng D, Guodong F, Lirong $\mathrm{J}$. The neurological damage of the abuse of laughing gas. Stroke and Nervous Diseases. 2018;25(2):173-178.

5. Sleeman I, Wiblin L, Burn D . An unusual cause of falls in a young woman. J R Coll Physicians Edinb. 2016;46:160-162.

6. Waters MF, Kang GA, Mazziotta JC, DeGiorgio CM. Nitrous oxide inhalation as a cause of cervical myelopathy. Acta Neurol Scand. 2005;112:270-272.

7. Keddie S, Adams A, Kelso ARC, Turner B, Schmierer $\mathrm{K}$, Gnanapavan $\mathrm{S}$, et al. No laughing matter subacute degeneration of the spinal cord due to nitrous oxide inhalation. J Neurol. 2018;265(5):1089-1095.

8. Hathout L, El-Saden S. Nitrous oxide-induced B12 deficiency myelopathy: Perspectives on the clinical biochemistry of vitamin B12. Journal of the Neurological Sciences. 2011;302:1-8.

9. Savage S, Ma D. The neurotoxicity of nitrous oxide: the facts and putative mechanisms. Brain Science. 2014;4:73-90. 